\section{From Critical to Transformative Pedagogy in Architectural Education}

\section{Kristin Jones}

Illinois Institute of Technology
Transformative pedagogy is a contemporary educational ideal intended to actively promote the transformation of the life and inner perception of the learner and his/her community. It emerged at the dawn of the 21st century from a line of counter-hegemonic thought that has been called emancipatory, liberal, radical or critical in the effort to chart a new direction for post-industrial education. This paper addresses the struggle of architectural education to maintain its aim as an emancipatory practice within an ever-evolving disciplinary culture.

\section{CRITICAL PEDAGOGY AND ARCHITECTURAL EDUCATION}

Freedom is not only a political ideal, it is also an educational ideal. ${ }^{1}$ Paulo Freire is probably the best known figure in critical pedagogy. Working with adult laborers in Brazil, Freire advocated "critical consciousness" as a necessary step to liberation from political oppression and for education aimed at becoming "more fully human." Freire advocated for dialogue and participatory action and raised awareness that our educational methods can be instruments of oppression. He referred to his method of education as "critical praxis" or liberation pedagogy. ${ }^{2}$

But the critical movement is said to have begun much earlier, some say with the philosophy of Kant. ${ }^{3}$ Kant considered the modern era "an age of criticism" when everything should be open to free and public examination and where "formal [universal] principles" are the foundation of free choice. ${ }^{4}$ According to the Stanford Encyclopedia of Philosophy, "The fundamental idea of Kant's 'critical philosophy'... is human autonomy." 5 The concept of freedom which was central to Kant's philosophy was not new to Western thought, however, tracing back through the religious conception of God as eternal light and salvation, (e.g. St. Augustine ${ }^{6}$ ), to the Platonic conception of the eternal Idea/Form. ${ }^{7}$ Kant reformulated the Platonic conception of knowledge in his "transcendental idealism," ${ }^{8}$ expounded in his philosophical critiques which reflected contemporary reason and analytical style. "Critical philosophy," as it came to be known, was essentially a modern look at the foundations of knowledge.

Although Kant's work was a speculative form of philosophy, it influenced the arts and other activities in the socio-political arena. Two schools of thought which stemmed from critical philosophy (see Figure 1) had a defining influence on modern architectural education, espe-cially as it was developed in the U.S. One was meta-theory and the other was critical theory. As different as they are, both can be con-sidered outcomes of critical philosophy in that both trace back to the philosophy of Kant and are grounded in education as an emanci-patory practice.

The Preliminary Course ("Vorkurs") of the German Bauhaus is a familiar pedagogical manifestation of the principles-oriented thinking characterized by meta-theory and embodied in works like Hilbert's axiomatic meta-mathematics, ${ }^{9}$ a theory later furthered by Walter Peterhans ${ }^{10}$ as meta-aesthetics or axiomatic aesthetics. Metathinking related to Kant's philosophy in that it looked for the universal principles underlying distinct fields of knowledge and laid those principles open to public examination. So-called basic or foundation 


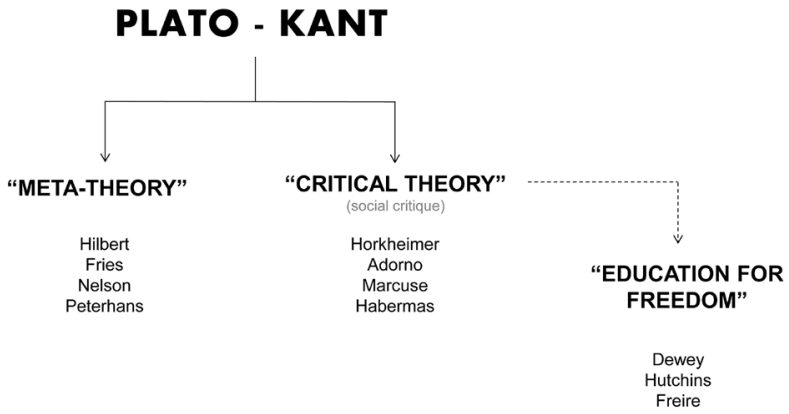

Figure 1. Critical influences on modern architectural education.

courses were built on such principles and aimed to teach the principles of form and color to all students of the visual arts. In contrast to traditional training which drew on an established canon of orders and precedents as the basis of design, basic courses sought to develop skills and judgment by breaking the field of art down into its fundamental principles or elements and exposing them. The approach to art education through fundamentals was thought to facilitate unbiased training, providing access to the visual language of art while allowing a student to develop authentic and original expression. Insofar as basic pedagogy was based on universal principles and freedom of expression, it can be considered a form of critical pedagogy. ${ }^{11}$

Within German academia, space also grew for public critique of social conditions. At the Institute of Social Research in Frankfurt, for example, academics including Horkheimer, Adorno, and Marcuse developed critiques on modernity and capitalism. Around the same time that Bauhaus ideas were making their way to the U.S. through Gropius, Mies, Peterhans and Albers, the Frankfurt school of "critical theory" was also migrating to New York city. Taken up at Columbia University and the University of Chicago, proponents like John Dewey and R.M. Hutchins ${ }^{12}$ focused the microscope of social critique on the educational institution. Although critical pedagogy usually refers to a more hands-on, participatory approach, insofar as academic critical theorists' teaching and writing is grounded in an emancipatory ideal, raises awareness of oppressive conditions, and is open to free and public examination, it can also be considered a form of critical pedagogy. ${ }^{13}$

From foundation courses to history-theory courses, the influence of meta-theory and critical theory on architectural education throughout the 20th century is evident. The more recent shift in discourse from "critical" to "transformative" pedagogy arose out of the perceived need to distinguish 20th century versions of pedagogy, which was focused on problems of industrialization and adapting to a global marketplace, from pedagogy for a post-industrial world.

\section{TRANSFORMATIVE LEARNING THEORY}

As much as an emancipatory ideal underpinned the philosophy of early modern architectural education, the same ideal eventually called into question the universal form and narrative it had taken.
Subjectivity and diversity emerged as radical issues at the end of the century, and disrupted the claims to universality upon which modern architectural education was based, (see Figure 2). Meanwhile, the nega-tive effects of industrialization became increasingly difficult to ignore. Globalization and postmodern critique both challenged us to embrace difference and incorporate new experiences and ideas into broader perspectives. The new millennium seemed to signal a shift in both the way we think and what we see as key problems. The transformative movement in education is a response to these perceived changes.

One of the earliest articulations of transformative learning theory was made by Jack Mezirow. Simply put, "Transformative learning is the process of effecting change in a frame of reference." ${ }^{14}$ Our experiences create frames of reference that define our life world. Based on those frames of reference, many of us have a strong tendency to reject ideas that do not fit our preconceptions, labeling them as nonsense, mistaken, or irrelevant. Mezirow noticed that when confronted with a "disorienting dilemma," transformative learners instead move toward a frame of reference that is "more inclusive, discriminating and integrative of experience." ${ }^{15}$ This self-critical endeavor is aimed at transformative action, toward transcending one's own history and circumstance.

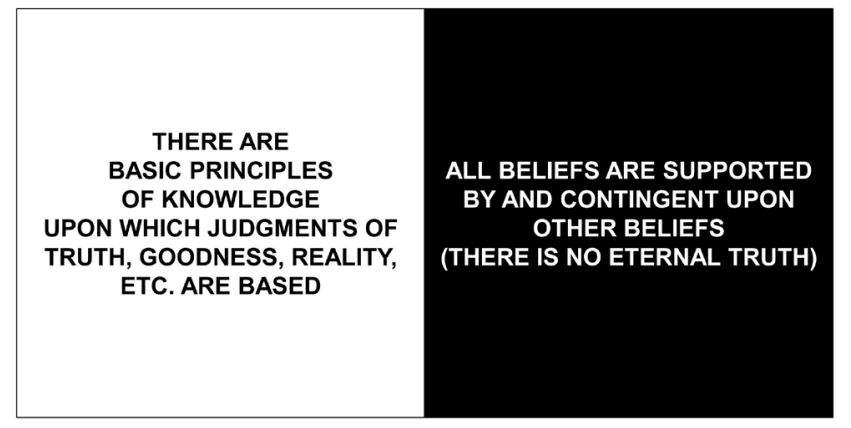

Figure 2. Modern-Postmodern dilemma. ${ }^{16}$

Although early on, the distinction between transformative learning theory and critical pedagogy was less clear, it came to signify a more inclusive theory of learning and greater environmental consciousness for the new millenium. Edmund O'Sullivan's description of transformative learning, for example, addressed the interrelationship between learning and the environment, and more broadly, the individual and the cosmos. In his 1999 book, Transformative Learning: Educational Vision for the 21st Century, ${ }^{17}$ he identified four stages in the development of what he called a "critical transformative perspective" (see Figure 3). In the first stage, we are unaware of anything wrong with the predominant worldview and direction. We are going about trying to conform to and succeed within the predominant social system. Second, as we begin to see cracks in the logic of the predom-inant system or its narratives, an emergent consciousness arises within us. He cites, as an example, noticing the dichotomy between "wonderworld" commercial rhetoric and "wasteworld" earth-cri-sis reality. As we begin to question the predominant worldview, our 


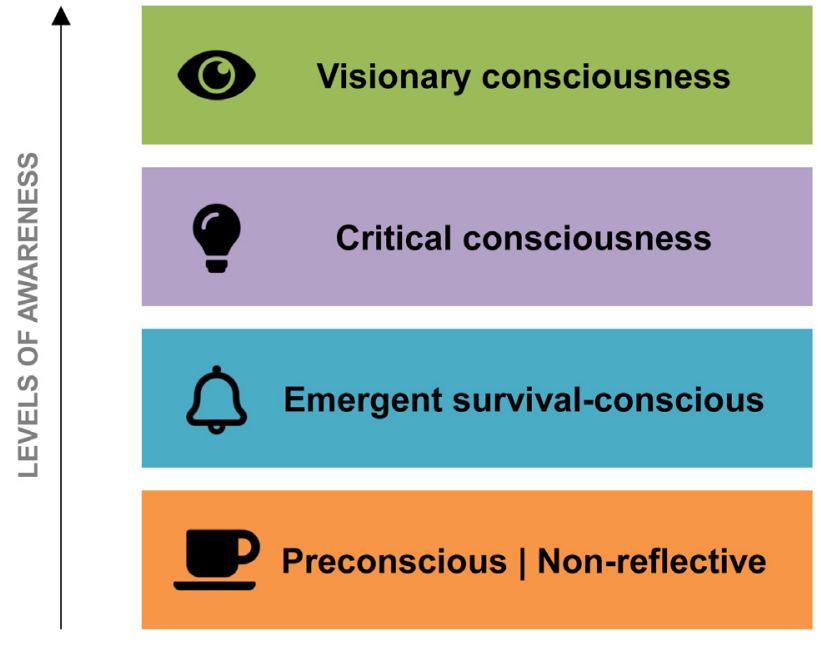

Figure 3. O'Sullivan's stages of perspective transformation.

survival-consciousness experiences stages of denial, despair and grief as we process the loss of a former world which is no longer tenable.

In critical consciousness, the predominant worldview is replaced with a transcendent perspective that acknowledges the challenge or disruption. O'Sullivan suggests that rather than "restructure our schools to help students to become competitive in the global sphere," our task is to raise awareness of the 20th century's "industrial trance state" and to choose a more ecological path. With this in mind, it is not enough for 21st century education to strive for equal opportunity for all to participate in the global-industrial-capitalistic world order, he says. If we are to transcend the destructive nature of the global-industrial-capitalistic economy, we must recognize the role we and our educational institutions are playing in its perpetuation.

The last stage of transformative learning, "visionary consciousness," concerns the transformation of the critical perspective into

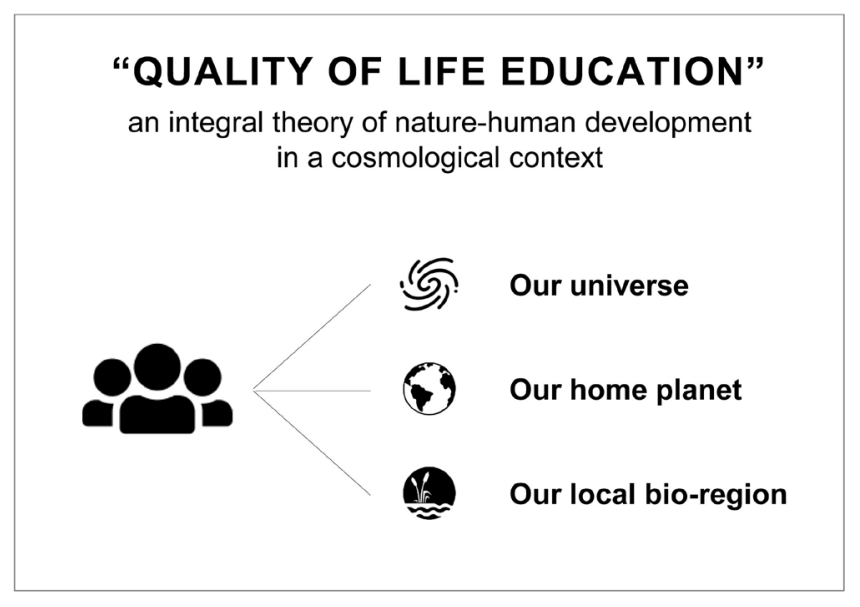

Figure 4. O'Sullivan's "quality of life" education. a vision for action. Drawing on a variety of sources ranging from holistic pedagogy, eco-literacy and indigenous wisdom traditions, to contemporary science and feminist theory, O'Sullivan's vision for education is a radical departure from the status quo. It is a more holistic theory of education acknowledging not only the damage to our physical environment, but also the devastating spiritual consequences of our fragmented modern thought and ways of life. O'Sullivan envisions a "quality of life education" which honors bio-diversity and the sacred web of life, or what he calls "an integral theory of nature-human development in a cosmological context." His suggestion for 21 st century education is learning about ourselves and what unifies and sustains us all, through our local bio-regions, the history of our home planet, and our universe (see Figure 4). The role of educator in this framework shifts from teaching students to function within an exist-ing social order to visionaries working to bring about radical transfor-mations in social thought and culture.

\section{TOWARD TRANSFORMATIVE PEDAGOGY IN ARCHITECTURAL EDUCATION}

The growing awareness of our environment and greater demand for thinking that is less polarized and more inclusive, or transformative, compels us to reflect on our pedagogy. Because the practice of architecture requires us to develop an ability to think about our world in different scales and from different points of view, and accustoms us to thinking about particulars as local conditions within broader contexts, it is a natural framework for transformative pedagogy. Using the connection that O'Sullivan made between perspective transformation and an integral nature-human theory of education as a point of departure, the following discussion highlights three principles of transformative pedagogy in the context of architectural education: teacher perspectives, methods of instruction, and curriculum, (see Figure 5).

\section{TRANSFORMING TEACHING PERSPECTIVES}

Transforming the world through architectural education begins with teachers becoming transformative learners. Like everyone else, architectural educators have inherited some deep-seated habits of mind and action. Learning from Giroux ${ }^{18}$ and Mezirow, ${ }^{19}$ architectural educators will need to be cognizant of our roles as co-creators of a social and environmental reality. We will need to reflect deeply on our own inherited patterns of mind and action, confront our "disorienting dilemmas," and develop visions for action.

We can start with understanding and appreciating the models of general and architectural education with which we were raised, and reflecting critically on how they have shaped our thinking and views on education and life. In doing so, we emancipate ourselves from our historical circumstances and begin to develop a critical perspective on education. For the transformative teacher, the question is less about rejecting earlier methods of education than it is understanding how different methods impact learning, that we might draw on them more adeptly in our own instruction.

Perhaps one of the most persistent disorienting dilemmas we face in architecture is the reconciliation of art and science. Between 

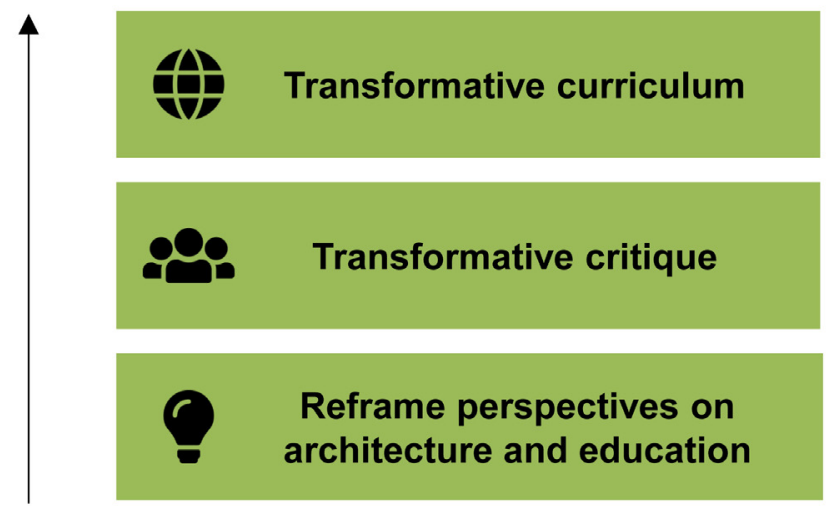

Figure 5. Principles of transformative pedagogy in architectural education.

Jean Mignot's "Ars Sine Scientia Nihil Est [Art without Science is Nothing]"20 (14th century) and C.F. Snow's "The Two Cultures"21 (1959), we have heard the call for more inclusive thinking. However, much of our contemporary architecture betrays that we continue to grapple with how to integrate thinking about science and art. If we want to move beyond architecture that is, for example, texturally rich but structurally absurd or cost-effective but ugly, we will need to continue to develop and foster more inclusive perspectives on architecture. Recognizing this and other ways in which polarized thinking is destroying or stunting our conceptions of architecture is a way for teachers to bring critical consciousness to the discipline, emancipate architectural expression, and move toward visions for action.

\section{TRANSFORMATIVE CRITIQUE}

Thinking about learning as transformation also applies to our instructional approach. Much of the critique used in architectural education is constructive criticism, which identifies problems in a student's solution, and is often coupled with a helpful suggestion toward resolution. By contrast, transformative critique centers less on the solution and more on reframing student perspectives. The teacher works to foster students' latent talents and help facilitate their discovery of underlying principles which were once hidden from view. Its objectives include learning how to question, growing into broader points of view, and developing expression. Its features include inclusivity, space for active learning and dialogue, and dynamic scaffolding.

A transformative classroom respects and integrates differences in participants' histories and development, and uses those differences to create richer and more meaningful learning environments. In resisting the tendency to reject students' ideas that do not fit with our preconceptions and opening our minds to unimagined possibilities, we invite entirely unique and student-owned solutions while we expand and clarify our own readings of the world.

Dynamic scaffolding is the link helping students make a connection between their unique histories and experiences and an existing architectural culture of practice. Whereas "student-centered" discourse sometimes downplays the contribution of the teacher, dynamic scaffolding acknowledges and draws on the teacher's experience to facilitate the learning process. ${ }^{22}$ The goal of dynamic scaffolding is for our students to develop their own abilities to identify an architectural problem, evaluate solutions, and make decisions; to become self-reliant. It is dynamic in that it responds to students' individual needs, only as the need arises.

In order to provide effective dynamic scaffolding, understanding the creative process and analytical methods we use to make good judgments and proposals is necessary. Becoming aware of and introducing our students to the methods we use to expand our thinking and refine our solutions (e.g. open experimentation, dialogical comparison, controlled comparison), ${ }^{23}$ gives our students tools they can learn to apply and later adopt. When we read students' design proposals for what they are missing, resist the tendency to provide "the answer," and think about what they need to make better decisions, our critique can become transformative.

\section{TRANSFORMATIVE CURRICULUM}

Our curricula are our collective visions for action representing specific cultures of architectural scholarship and practice. O'Sullivan's vision of an integral nature-human paradigm utilizes a scale-based curricular model, (e.g. bio-region, planet, universe), to help us envision our own lives and the movements of our people in the context of broader evolutionary histories. ${ }^{24}$ The scale-based model is a familiar framework in architectural education. Architectural design curricula are usually scale-based, often starting with a small shelter, advancing to a house, followed by an institutional building and perhaps a group of buildings. Planning curricula too often utilize a scale-based model. For example, Hilberseimer's City and Regional Planning program at IIT began with room studies, advanced to single-family dwellings of different sizes, and culminated in regional-scale human settlement studies. ${ }^{25}$ Although the scale-based curriculum is usually thought to be significant in terms of representing different scales of practice in architecture and planning, it is also significant in terms of educational theory, as O'Sullivan's work brings to light.

O'Sullivan's nature-human paradigm reminds us that the frameworks we use in architectural education, including the scale-based models and the axiomatic frameworks of the basic courses, are also important in that they foster broader perspectives and thinking across different scales and contexts. These frameworks are a means of organizing key problems in architectural education to form a curriculum. Conceived from both disciplinary and transformative perspectives, the projects that define those frameworks are significant in multiple ways -- for inculcating students into an existing disciplinary practice, for developing critical-transformative perspectives, and as integrative pedagogy. In addition to their formal signficance, our studio projects are increasingly being viewed as opportunities to both take in and give back to the community, and students and teachers are finding ways to use architectural projects to engage with a broader community of professionals and public. 


\section{CONCLUSION}

According to UNESCO, the world has reached "a broad consensus that quality education in the twenty-first century means learning how to live and work sustainably." ${ }^{26}$ Architectural education is aligned with UNESCO's vision of quality 21st century education through Global Citizenship Education (GCE) and Education in Sustainable Development (ESD) ${ }^{27}$ in several ways. The National Architectural Accrediting Board (NAAB) requires that accredited schools educate students in "History and Global Culture", "Cultural Diversity and Social Equity", and "Environmental Stewardship".28 The Architect Registration Exam (ARE) questions would-be architects on environmentally-conscious design choices. ${ }^{29}$ Databases of sustainable projects, resources for making better sustainable material choices, and energy modeling tools are readily available. ${ }^{30}$ Incentives to promote ESD and GCE (and community oriented design) are increasing,, ${ }^{31}$ and continuing education programs concerning "green" issues proliferate.

However, recent social critique suggests that 21st century education also needs something that GCE and ESD don't quite capture. Compare O'Sullivan: "As a result of globalization, rootlessness, transitoriness and dispossession are the fall-out of an increasing number of communities; people must move to find better jobs, corporations move to find cheaper labour. Products for consumption move thousands of miles to reach global markets, fashion changes with each season, and neighbourhoods where people grew up shift within a generation. Our sense of belonging to a stable community and our security are lost in the shuffle of accelerated change and mobility," ${ }^{2}$ with David Orr: "The average American moves ten times in a lifetime, and spends countless hours at airports and on highways going to places that look a great deal like those just left behind. Our lives are lived amidst the architectural expressions of deplacement: the shopping mall, apartment, neon strip, freeway, glass office tower, and homogenized development - none of which encourage much sense of rootedness, responsibility and belonging." 33 Some say this lack of a sense of belonging and responsibility is the root of many of our contemporary problems.

According to UNESCO's website, "While the world may be increasingly interconnected, human rights violations, inequality and poverty still threaten peace and sustainability." ${ }^{34}$ In the U.S. alone, rising wealth inequality ${ }^{35}$ undermines our sense of community, the safety of citizens is questionable (e.g. sexual harassment, domestic violence, hate crimes, and two decades of mass-shootings), and suicide deaths in both men and women are on the rise. ${ }^{36}$ Given that the world is not getting smaller without difficulty, it seems the questions of belonging and being free should be also be central to discourse on 21st century architectural education.

My hunch is that transformative theory points to ways in which architectural education can integrate issues of practice and education to advance more inclusive and humane ways of life. This paper, and the shift from critical to transformative pedagogy it describes, demonstrates that our struggle to remain an emancipatory practice in an ever-evolving disciplinary culture is not our own struggle, but the continual struggle of education. Even as architectural practice increasingly moves toward sustainable development and global citizenship in the 21st century, education's critical and transformative purpose remains distinct, essential, and perhaps even timeless. As we continue to reflect on, bring to light, and transcend destructive and oppressive social and environmental conditions, transformative pedagogy offers hope in new ways to foster belonging and freedom.

\section{Notes}

1. See for example, Paulo Freire, Pedagogy of the Oppressed (New York: Continuum, 2000); bell hooks, Teaching to Transgress: Education as the Practice of Freedom (New York: Routledge, 1994); Robert Maynard Hutchins, Education for Freedom, (Baton Rouge, LA : Louisiana State University Press, 1943).

2. Freire, Pedagogy of the Oppressed.

3. See for example, Encyclopeadia Britannica (britannica.com), which dubs Kant the "father of critical philosophy."

4. See Michael Rohlf, "Immanuel Kant," in The Stanford Encyclopedia of Philosophy, edited by Edward N. Zalta, Metaphysics Research Lab, Stanford University, (Spring 2016): "To some limited extent we are capable of rationally shaping our desires, but insofar as we choose to act in order to satisfy desires we are choosing to let nature govern us rather than governing ourselves (5:118). We are always free in the sense that we always have the capacity to govern ourselves rationally instead of letting our desires set our ends for us. But we may (freely) fail to exercise that capacity. [...] In contrast to material principles, formal principles describe how one acts without making reference to any desires. This is easiest to understand through the corresponding kind of imperative, which Kant calls a categorical imperative."

5. Rohlf, "Immanuel Kant," in The Stanford Encyclopedia of Philosophy.

6. St. Augustine acknowledges Plato as the philosopher most closely aligned with Christianity in St. Augustine, City of God (London: Penguin Books, 2003).

7. Concerning freedom from the error and misunderstanding that accompanies faulty temporal knowledge - according to Plato, the Stanford Encyclopedia of Philosophy explains, "The world that appears to our senses is in some way filled with error, but there is a more real and perfect realm, populated by entities (called "forms" or "ideas") that are eternal, changeless, and in some sense paradigmatic for the structure and character of the world presented to our senses." See Richard Kraut, "Plato," in The Stanford Encyclopedia of Philosophy, ed. Edward N. Zalta, Fall 2017 (Metaphysics Research Lab, Stanford University, 2017), https://plato.stanford.edu/ archives/fall2017/entries/plato/.

8. "Transcendental idealism" is the process by which Kant explained that experience is transformed through synthesis into higher "universal" or non-contingent knowledge, not unlike Plato's Ideas/Forms. See Immanuel Kant, Critique of Judgement (Oxford: Oxford University Press, 2007).

9. David Hilbert, "Axiomatic Thinking," trans. J. Fang, Philosophia Mathematica VII, no. 1-2 (1970): 1-12, https://doi. 
org/10.1093/philmat/s1-7.1-2.1.

10. Walter Peterhans, Professor of Visual Training at IIT (19381960) and former director of the Bauhaus Department of Photography (1929-1933), founded the Visual Training course at IIT dealing with visual perception and aesthetic judgment. See Walter Peterhans, "Fragment on Aesthetics," Ratio, Basil Blackwell, Vol. III (1961) for an introduction to his concept of axiomatic- or meta-aesthetics.

11. The basic course and the thinking behind it inspired the modern canon of art school texts, from early examples like Denman Ross' A Theory of Pure Design, Harmony, Balance, Rhythm (1907) and Roger Fry's Vision and Design (1920) to mid-century Johannes Itten's The Art of Color (1961), Gyorgy Kepes' Language of Vision (1944), and Maurice de Sausmarez' Basic Design: The Dynamics of Visual Form (1964), to later examples like Wucius Wong's Principles of Form and Design (1993).

12. See John Dewey and Irwin Edman, John Dewey: His Contribution to the American Tradition, Makers of the American Tradition Series (Indianapolis: Bobbs-Merrill, 1955). At the University of Chicago, R.M. Hutchins established the Committee on Social Thought while advocating Education for Freedom, (see Hutchins, Education for Freedom).

13. Modern educational reform was motivated by new views on learning and childhood development influenced by social critique (i.e. critical theory) and psychology both. Familiar educational technologies like Fröbel's blocks and Montessori's manipulatives reflected new thinking about the basics of knowledge and learning, while later progressive educators including Steiner and Dewey advanced childhood development theories to what they called the whole child, and advocated the development of intellectual, practical and artistic character, still toward developing free individuals, but within the social context of civic responsibility. Together, cognitive development and behavior theories coupled with notions of children's rights and literacy shifted modern schooling away from traditional authoritarian models toward more student-centered models at all levels of schooling.

14. See Jack Mezirow, "Transformative Learning: Theory to Practice," New Directions for Adult \& Continuing Education 1997, no. 74 (Summer 1997): 5; and Jack Mezirow, "Perspective Transformation," Adult Education 28, no. 2 (January 1978): 100-110, https://doi. org/10.1177/074171367802800202.

15. Mezirow (1997).

16. See Oswald Spengler, Decline of the West: Volume I, Form and Actuality, Re-issue (Knopf, 1996) and JeanFrancois Lyotard, The Postmodern Condition: A Report on Knowledge, 1st ed. (Univ Of Minnesota Press, 1984) for postmodern perspectives.

17. Edmund O'Sullivan, Transformative Learning: Educational Vision for the 21st Century (London; New York : New York: Zed Books, 1999).

18. In Henry A. Giroux, Schooling and the Struggle for Public Life:
Critical Pedagogy in the Modern Age (Minneapolis : University of Minnesota Press, 1988), Giroux states "...Educational workers ... are not only born into a specific historical context; they embody its history in varying ways both as a state of consciousness and as sedimented experience, as a felt reality. To what degree they critically mediate that history and its attendant ideology is another issue. Thus, educational practitioners can be viewed as not only products of history but producers of history as well. And it is this dynamic process of socialization that links them and the schools in which they work to the larger society." Part of critical transformative practice, therefore, is recognizing and including in our education time to reflect on our educational inheritance, in order to bring it into conscious awareness.

19. See Mezirow (1978) for an introduction to the "disorienting dilemma".

20. See Ananda K. Coomaraswamy, "Ars Sine Scientia Nihil," in Figures of Speech, Figures of Thought (World Wisdom, 2007); and James Ackerman, "'Ars Sine Scientia Nihil Est' Gothic Theory of Architecture at the Cathedral of Milan," The Art Bulletin 31, no. 2 (June 1949): 84-111. The "art without science" critique is a plea against severing the connection between knowledge (science) and knowledge transformation/expression (art).

21. C.P. Snow, "The Two Cultures and the Scientific Revolution," The Rede Lecture, Cambridge, 1959 (Cambridge University Press, 1959). The "two-cultures" characterizes the separation in thought and practice between the scientific-empirical and the literary-artistic disciplines.

22. One study described the dynamic scaffolding process as akin to child rearing practices, "managing relationships and creating opportunities for development," leading to the finding that: "A typical transformative class could be considered a blending of teacher centered and student centered approaches." Further, this study found that "the youth of high school-age students [...] may be more of an asset for meeting transformative goals than an impediment," contrary to the belief that transformative learning is best suited for adults. See Marinda K. HarrellLevy, Jennifer L. Kerpelman, and Daniel J. Henry, "Practices of Exemplary Transformative Teachers, as Perceived by Students Transformed by an Urban High School Social Justice Course," The Urban Review 48, no. 1 (March 1, 2016): 73-100.

23. For more on methods of dialogical and controlled comparison, see Kristin Jones, "Research in Architectural Education: Theory and Practice of Visual Training," Enquiry: A Journal for Architectural Research 13, no. 2 (December 12, 2016), https://doi.org/10.17831/enq:arcc.v13i2.404.

24. O'Sullivan, Transformative Learning, p. 194.

25. See, for example, Ludwig Hilberseimer, The New Regional Pattern : Industries and Gardens, Workshops and Farms, (Chicago: P. Theobald, 1949), The New City: Principles of Planning, (Chicago: P. Theobald, 1944), and Alfred Swenson and Pao-chi Chang, Architectural Education at IIT, 1938-1978 
(Chicago, IL: Illinois Institute of Technology, 1980).

26. Leicht, A., J. Heiss, and W.J. Byun, eds., Issues and Trends in Education for Sustainable Development: Education on the Move, (Paris: UNESCO Publishing, 2018).

27. In 2015, UNESCO published 17 sustainable development goals to reach by 2030 including "quality education". In addition to basic numeracy and literacy, UNESCO identified Education for Sustainable Development (ESD) and Global Citizenship Education (GCE) as key elements. See Qian Tang and UNESCO, Rethinking Education: Towards a Global Common Good? (Paris: UNESCO Publishing, 2015).

28. National Architectural Accrediting Board, Inc., "2014 Conditions for Accreditation," July 18, 2014.

29. "Project Planning \& Design," NCARB - National Council of Architectural Registration Boards, November 14, 2016, https://www.ncarb.org/pass-are/are5/prepare/ project-planning-design.

30. For example, the Architecture 2030 Palette, Carbon Smart, and Sefaira are available online.

31. Examples in education include the DOE's international Solar Decathlon competition, ACSA/AIA COTE Top Ten for Students Competition for projects working toward carbon-neutral design award, and the ACSA Collaborative Practice award.

32. O'Sullivan, Transformative Learning, p.245.

33. David W. Orr, Ecological Literacy: Education and the Transition to a Postmodern World (Albany: State University of New York Press, 1992).

34. See https://en.unesco.org/themes/gced.

35. See Chad Stone, Danilo Trisi, Arloc Sherman, and Roderick Taylor, "A Guide to Statistics on Historical Trends in Income Inequality," Center on Budget and Policy Priorities, (February 16, 2018), and Chuck Collins and Josh Hoxie, "Billionaire Bonanza: The Forbes 400 and the Rest of Us," Institute for Policy Studies, (December 1, 2015).

36. Based on 2016 data by World Health Organization (WHO), "GHO | By Category | Suicide Rates, Age-Standardized - Data by Country," (WHO, 2018), http://apps.who.int/ gho/data/view.main.MHSUICIDEASDRREGv?lang=en (last updated 7-17-2018). 